\title{
A FORMAÇÃO DE PROFESSORES NO CONTEXTO DAS TENDÊNCIAS PARA INTERNACIONALIZAÇÃO DA EDUCAÇÃO SUPERIOR A DISTÂNCIA*
}

\author{
Juliana GuIMARÃes Faria, \\ da Universidade Federal de Goiás \\ Mirza Seabra TOSCH, \\ da Universidade Estadual de Goiás
}

\begin{abstract}
REsUMo: O texto indaga sobre a relação da educação a distância com as políticas de internacionalização da Educação Superior e sobre a inserção da formação de professores nessa realidade. Mostra que a educação a distância está em plena expansão, principalmente nos cursos de formação de professores, e imersa no processo de liberalização do comércio dentro da OMC. Nesse processo de liberalização, a EAD vem sendo vista como um bem comercializável, por suas características de transfronteirização e baixo custo. Levanta-se a questão da necessidade de se discutir a EAD no Brasil para além de um bem de consumo e a importância dos debates em torno de suas condições de oferta, objetivos e regulamentação.

PalAVRAS-ChAVE: Educação Superior a distância. Internacionalização da educação. Formação de professores.
\end{abstract}

INTRODUÇÃO

\footnotetext{
"No hay uma sociedad de la información. Hay muchas sociedades de la información y depende de nosotros que identifiquemos la que esperamos habitar en el futuro y trabajar para que pueda existir." (AndRew Feenberg)
}

Busca-se neste texto' fazer uma reflexão sobre a Educação a Distância (EAD) no contexto das políticas para a Educação Superior. Questiona-se a relação da EAD com as políticas de internacionalização desse nível educacional e

* Artigo recebido em 15/08/2010 e aprovado em 19/09/2010. 
sua liberalização na Organização Mundial do Comércio (OMC). A liberalização, ou internacionalização da educação, tem sido palco fecundo de debates e interesses político-econômicos. A discussão perpassa pelas preocupações de cunho social, cultural e de caráter de bens e serviços. O fato é que a educação já está caracterizada como um serviço dentro do Acordo Geral de Comércio e Serviços - General Agreement on Trade in Services (GATS) - desde 1994. O que não se definiram foram mecanismos de funcionamento desse processo de livre comércio da educação e, portanto, esta está ainda em debate entre os países.

O texto mostra inicialmente que a Educação Superior está em crise e, no andamento dos debates, encontra-se o processo de liberalização do comércio. Nesse processo de liberalização, a EAD está sendo vista como bem comercializável, por suas características de transfronteirização e baixo custo. Neste estudo, são feitas análises com base em documentos da Unesco, Banco Mundial (BM) e MEC que versam sobre a Educação Superior. Levanta-se a questão da necessidade de se discutir a educação a distância no Brasil e a importância dos debates em torno de suas condições de oferta com mais qualidade social e cultural para a nação. Destaca-se, após a análise dos documentos oficiais, que a internacionalização da Educação Superior é uma questão polêmica e preocupante. Ela se mostra com caráter neoliberal à medida que serve aos interesses mercadológicos e está na pauta da Organização Mundial do Comércio (OMC).

Podemos destacar nesse processo alguns aspectos: a) as negociações na OMC são feitas de forma que envolvem outros setores em um mesmo pacote, como a agricultura, turismo, telecomunicações, que possuem outra natureza se comparadas à educação; b) a Unesco e os dirigentes das instituições públicas de ensino superior declaram a complexidade desse processo e as consequências de diversas naturezas que envolvem a liberalização mercadológica, mostrando-se contrários a essa postura; c) o Banco Mundial. no entanto, tem outra orientação, destacando a necessidade de diversificação de financiamento das instituições públicas, inserindo a educação a distância como forma mais econômica e eficiente; $d$ ) a regulação é vista como a selagem de iniciação ao processo de livre comércio e não se discute regular e avaliar na perspectiva de emancipação e formação as instituições que praticam educação a distância.

Nesse contexto, a educação a distância é contraditória. Ao mesmo tempo em que é suscetível à mercantilização, tem méritos que precisam ser considerados: democratização do acesso, incorporação das tecnologias, 
mudanças nos currículos, mediações pedagógicas baseadas no diálogo, formação para a autonomia, dentre diversos outros aspectos positivos.

\section{Crise na EducaÇão Superior}

A universidade enfrenta questionamentos sobre sua atuação e sobre as contradições presentes em sua prática. Há questionamentos em relação à dicotomia entre produção de alta cultura e produção de cultura popular, em relação à educação e à preparação para o mundo do trabalho, em relação à formação teórica e prática, em relação a seu financiamento público e atuação social. Essa crise da universidade permeia a Educação Superior e os organismos multilaterais têm trazido indicações de soluções nomeadamente neoliberais como instrumento para reforçar o mercado capitalista.

Para Sguissardi (2000), os questionamentos em relação ao ensino superior no Brasil giram em torno de um quadro precário e desafiador. Destaca o autor:

de fato o sistema de Educação Superior de há muito, isto é, desde suas origens, divide-se em universidades de pesquisa (a minoria) e universidades ou IES de ensino e que mesmo a exigência legal de até o ano de 2004 todas as IES organizadas como universidades terem $30 \%$ de seu corpo discente qualificado com grau de mestre e doutor e contratado em regime de tempo integral não garantirá a existência de atividades de pesquisa na maioria das universidades; e, finalmente, se a pesquisa porventura vier a existir em escala significativa, isto não significa garantia suficiente de associação ensino-pesquisa no nível da graduação, pois, como se sabe também, a pesquisa na universidade tende a confinar-se aos cursos e laboratórios de pós-graduação (p. 21-22).

De fato, a crise vivenciada pela Educação Superior está escorrendo pelas mãos das próprias instituições e está na pauta de discussões políticas e econômicas. A Educação Superior não está sendo vista como mais um setor da educação. De acordo com Marco Antonio Dias (2004), ela é vista pelos organismos multilaterais como"peça fundamental de um sistema holístico que deve se tornar mais flexível, diversificado, eficiente e responsável diante da economia do conhecimento" (p. 895). E, por isso, os organismos multilaterais tentam traçar políticas para sua reforma nos diferentes países.

O fato de os organismos multilaterais se preocuparem com o ensino superior incide sobre o reconhecimento do importante papel desse nível educacional para o desenvolvimento social e econômico e sobre o questionamento da legitimidade das instituições para dar conta de corresponder 
ao anseio da sociedade, do Estado e do sistema capitalista. Os objetivos da Educação Superior começam a ser traçados pelos organismos multilaterais para serem seguidos pelos países em suas reformas educacionais.

Os objetivos da universidade começam a ser abalados e colocados em pauta na discussão do ensino superior. Santos (1997) aponta que os objetivos da universidade foram efetivamente abalados, pela primeira vez, na década de 1960, perante pressões e transformações vividas pela sociedade. No entanto, a formulação dos objetivos naquela época manteve notável continuidade: "os três fins principais da universidade passaram a ser a investigação, o ensino e a prestação de serviços" (p.188). De acordo com o autor, foi nas políticas universitárias concretas que alterações foram consolidadas e que eclodiu uma multiplicidade de funções para a universidade, muitas vezes contraditórias entre si. "A explosão das funções foi, afinal, o correlato da explosão da universidade, do aumento dramático da população estudantil e do corpo docente, da proliferação das universidades, da expansão do ensino e da investigação universitária a novas áreas do saber" (SANTOS, 1997, p. 188).

Assim, organismos multilaterais começaram a estabelecer funções para o ensino superior e para as universidades: desde o fornecimento de mão-de-obra qualificada até a preparação de lideranças sociais. Nos últimos anos, essa discussão tem sido mais intensa e tem movimentado os países, principalmente com a educação entrando no campo dos serviços a serem liberalizados comercialmente entre os países ligados à Organização Mundial do Comércio.

Nesse contexto de crise, as políticas de Educação Superior têm sido colocadas em pauta e as propostas dos organismos multilaterais passam a entrar na grade das discussões entre os países, passando a influenciar as políticas educacionais. A busca pelo ensino superior tem crescido nos últimos anos. De 1997 para 1998 houve um crescimento de 9\%, equivalente ao atingido pelo sistema em toda a década de 1980 (BRASIL, 2001, p. 61). De 1991 a 2002, as vagas oferecidas nos vestibulares cresceram mais de 200\%, segundo dados do Inep (BRASIL, 2004), passando de 517 mil para 1,6 milhão.

Os dados do Inep, bem como o diagnóstico apresentado pelo Plano Nacional de Educação, indicam que há uma distribuição desigual das vagas, fazendo com que as instituições privadas presentes nas regiões mais desenvolvidas do país se ocupem de mais de dois terços das vagas oferecidas.

Segundo o Plano Nacional de Educação, a porcentagem da população de 18 a 24 anos que tem acesso ao ensino superior no país é de 12\%, constituindo-se numa das mais baixas da América Latina e causando a preocupação no tocante à meta de atingir até 2010 o percentual de $30 \%$ dos jovens 
entre 18 e 24 anos, como propõe o PNE, devendo 40\% do total das vagas ser oferecidas por instituições públicas. Entretanto, a meta 2 do PNE (BRASIL, 2001, p. 67), que propõe, inclusive, a criação de novos estabelecimentos de Educação Superior foi vetada. Isso é preocupante uma vez que incluir a EAD nas políticas de Educação Superior não implica ausência de espaços físicos, bibliotecas, laboratórios, professores, uma vez que se faz necessário espaço adequado para essa modalidade de ensino, em especial se o desejável não é ensino massificado, mas ensino de qualidade entendido como direito público dos cidadãos. Além disso, há análises que dão conta de uma eliminação progressiva das fronteiras entre a educação presencial e a educação a distância.

A EAD é citada no PNE como modalidade educativa que possibilita a ampliação de atendimento nos cursos presenciais, regulares ou de educação continuada. A Portaria n 4.059, de 10 de dezembro de 2004, regulamenta esse ponto ao possibilitar que $20 \%$ da carga horária dos cursos presenciais sejam oferecidas na forma semipresencial. Há uma compreensão entre os especialistas em EAD de que em poucos anos não haverá diferença entre essas duas modalidades, ambas sendo usadas em todos os cursos.

Vale destacar que os cursos a distância destinam-se, em sua grande maioria, à formação de professores. Dos 46 cursos de graduação a distância existentes em instituições autorizadas e credenciadas, 41 têm como objetivo formar professores.

O que aconteceu para que se ampliasse tanto a oferta e a demanda por graduação a distância? A aproximação do fim da década da educação, que torna obrigatória a formação em nível superior para professores, conforme a LDB aprovada em dezembro de 1996, pode ser uma das razões, uma vez que a maioria dos cursos se destina à formação docente. Vale lembrar a Lei do Fundef, que destinava $60 \%$ dos recursos, nos primeiros cinco anos, à formação de professores e à melhoria dos salários. Outra hipótese é a questão de gênero. As mulheres, que são maioria anos cursos de formação de professores, podem, concomitantemente, fazer o curso superior e cuidar dos filhos, sem as exigências de ausência do lar que um curso presencial exige.

\section{EDUCAÇÃo E TranSNACIONALIZAÇÃO}

A liberalização ou, como tem sido chamada, a internacionalização da educação, tem sido palco de fecundos debates e interesses político-econômicos. A discussão perpassa por preocupações de cunho social, cultural e relativo ao caráter dos bens e serviços. Como já foi dito, a educação já está caracterizada como serviço dentro do GATS desde o ano de 2004, restando apenas definir mecanismos de funcionamento desse processo de liberaliza- 
ção do livre comércio da educação e, portanto, esta ainda se encontra em debate entre os países.

Ranieri (2004) nos mostra que a internacionalização em si não é fato novo no ensino superior. A autora argumenta que fatos como acordos de cooperação entre universidades no mundo inteiro, associação entre instituições nacionais e estrangeiras, dentre outras, são situações que acontecem cotidianamente nas instituições. O que se discute é a liberalização do livre comércio da educação, principalmente da Educação Superior.

Na verdade a internacionalização é inerente ao desenvolvimento do ensino superior e a sua expansão é inevitável, diante da sociedade globalizada, seja em razão da facilidade com que hoje as pessoas se deslocam pelo mundo, seja em razão dos novos meios de comunicação, especialmente da internet, que permite o ensino a distância. (RANIERI, 2004, p. 7)

Para a autora, as primeiras universidades do mundo ocidental já tinham esse caráter internacional, com professores vindos de diversos países. A discussão deve centrar-se justamente no que vem de novo nesse processo de internacionalização associada à liberalização comercial da educação. $O$ E-learning, ou aprendizagem a distância, é visto pela autora como um fenômeno novo. A novidade está no fato de o aluno não ir à instituição, mas no de a instituição ir até o aluno. "Por meios eletrônicos, desvinculado de local físico, o aluno passa a ter instrução de nível superior." (RANIERI, 2004, p. 9) Outro fato novo, dentro do acordo firmado e discutido no âmbito da OMC, é a "visualização do conjunto de alunos, professores e instituições e, portanto, do sistema educacional mundial, como um mercado dentro do qual a educação pode ser comercializada, como qualquer outro bem, como qualquer outra mercadoria." (p. 10) Isso, sim, é preocupante. A educação a distância aparece como bem a ser comercializado e, mais, a formação de professores passa ao centro do palco dessas discussões, visto que grande parte dos cursos a distância no Brasil acontecem nesse campo.

É um campo conflituoso e submetido à especulação de mercado, especulação que, dentro do comércio internacional, é definida nos termos do quem pode mais, vai negociar melhor, tendo os demais que aceitar certas condições em troca de vantagens em outras áreas da comercialização de serviços. A educação, nessas condições, pode ter comprometidas não só sua situação como direito público, como também sua legislação e qualidade, uma vez que o lucro pode vir a ser a preocupação maior.

A Educação Superior é caracterizada como o alvo principal do mercado de liberalização econômica. 
É mais atrativo porque, em geral, não está sob monopólio do Estado, na maior parte do mundo. Com exceção dos países da Europa, que ainda oferecem ensino público em grande proporção, no contexto mundial o ensino superior não sofre o monopólio estatal, o que facilita as negociações. Além disso, o ensino superior proporciona imensa gama de alternativas, desde a graduação à pós-graduação stricto sensu, passando pelas diversas especializações, MBAs, cursos profissionalizantes, cursos para adultos e os próprios serviços de intermediação desses negócios entre os diversos países. (RANIERI, 2004, p. 11)

Assim, a educação passa a ser mais uma moeda de troca dentro da OMC em negociações que envolvem agricultura, turismo, telecomunicações, dentre outros itens constantes do Acordo firmado em 1994. A OMC é um fórum para negociações internacionais e espaço de administração e fiscalização desses acordos. E, nesta instância, poderíamos dizer que quatro países já apresentaram propostas para a educação entrar no livre comércio: Estados Unidos, Nova Zelândia, Austrália e Japão.

Vejam: Nova Zelândia, Estados Unidos e Austrália, países conhecidos nossos como experts em educação, sobretudo na de nível superior, na educação massiva de altíssima qualidade. Harvard abre um curso com Michael Porter, duzentas pessoas na sala, e nem por isto o curso perde qualidade. Em 2002, o Japão, de forma aparentemente conciliatória, sugere a liberalização do setor. No entanto, apresenta algumas restrições. A grande restrição japonesa é no sentido de que a qualidade do ensino no país tem que crescer. Quer dizer, quem quiser entrar, entra, mas tem que aumentar a qualidade. (GRISI, 2004, p. 19)

O fato é que a Educação Superior no Japão não tem muito a ser melhorado, mas, na América Latina, na África e em parte do Oriente Médio e da Ásia há muito a ser feito e passa a educação, então, a ser um campo livre e com grande potencial de melhora e, portanto, com grande potencial de mercantilização. Dessa forma, o que é primordial é a capacidade que o país tem para se preparar para esse processo de livre comércio da educação, preparar-se para ter condição de competir.

Flores Jr. (2004) ressalta que o setor de serviços não caminha sozinho. Na educação, por exemplo, o que alimenta o setor são os livros-texto, programas de computadores e educação a distância, aulas gravadas, novas metodologias para educação. Temos que todo setor de serviços é acompanhado de vários setores de bens.

Dessa maneira, é claramente perceptível que a educação a distância está no contexto das políticas para Educação Superior como bem poderoso e economicamente viável para o livre comércio do serviço educacional. É vista 
como bem que não apresenta custo com prédios, iluminação, investimentos em instalações físicas e pode atingir o mundo inteiro, com característica transfronteiriça: "é o comércio de serviço que cruza fronteiras e pode ser ajustado pelas telecomunicações e pelo transporte." (GRISI, 2004, p. 21)

Um estudo descrito em uma publicação do Banco Mundial em 1995 (La enseñanza superior: las lecciones derivadas de la experiencia) mostra que o custo aluno com a Educação Superior a distância é muito menor do que com o ensino presencial. Nessa mesma publicação, o Banco Mundial declara quatro orientações para a reforma do ensino superior nos países:

- Fomentar mayor diferenciación de las instituciónes, incluído el desorrollo de instituciónes privadas.

- Proporcionar inventivos para que las instituciónes públicas diversifiquen las fontes de financiamiento, por ejemplo, la participación de los estudiantes en los gastos y la estrecha vinculación entre el financiamiento fiscal y los resultados.

- Redefinir la función del gobierno en la enseñanza superior.

- Adoptar políticas que estén destinadas a otorgar prioridad a los objetivos de calidad y equidad. (BAnCo Mundial, 1995, p. 4)

Não é objetivo discutir as orientações do Banco Mundial, mas vale destacar que essas orientações se voltam para a flexibilização e privatização, quando referem à redefinição do Estado e à necessidade de diversificação nas formas de atuação e fontes de financiamento. E a educação a distância é apresentada como forma de se fazer ensino superior que traz diversificação às instituições.

O discurso do Banco Mundial é o de a Educação Superior a distância ser eficaz no aumento das possibilidades de acesso de grupos menos favorecidos. Além disso, a educação a distância é vista como forma eficiente de se desenvolver a educação permanente, inclusive com a formação de professores em serviço. Nesse mesmo documento, a educação a distância é relatada como crescente em países como Bangladesh, Corea, China, Filipinas, Índia, Indonésia, Paquistão, Sri Lanka e Tailândia.

Los programas de educación a distancia son generalmente mucho menos costosos que los programas universitários corrientes, dado el más alto número de estudiantes por maestro. Por ejemplo, en Tailândia, la proporción média es de 8:1 en las universidades estatales selectivas, en comparación con 745:1 en las universidades abiertas. Para apreciar debidamente los méritos relativos de las universidades abiertas y las instituciones corrientes, sería también útil comparar los resultados en cuanto al mercado de trabajo, 
pero no se dispone en general de datos comparativos a este respecto. (BANCO MUNDIAL, 1995, p. 37)

Percebe-se que educação a distância é vista como possuidora de vantagens significativas: é mais lucrativa, custa menos e é transfronteiriça tudo o que é preciso para ser viável em comércio internacional. É, enfim, um bem comercializável.

Muitas mudanças estão acontecendo, mas vamos ater-nos ao processo de transnacionalização da educação, que tem levando muitas instituições educacionais brasileiras a atuar em outros países, por meio da venda de seu patrimônio. Essas fusões chegam a superar o percentual de $50 \%{ }^{2}$, contrariando o que prevê o Projeto de Lei de Reforma Universitária que se encontra no Congresso Nacional para votação, no qual é de $30 \%$ o limite para que empresas estrangeiras tenham participação em instituições educacionais. Essas vendas funcionam como um "comer pelas beiradas", ou seja, ir chegando aos poucos não se importando, em especial do lado brasileiro, com as consequências desses atos para o país.

A fim de ficarem mais fortes economicamente e de facilitar o ingresso de capital estrangeiro no país, essas verdadeiras empresas que se escondem sob o qualificativo educativas buscam agora a Bolsa de Valores. Em apenas cinco meses de 2007, quatro instituições de ensino superior no Brasil decidiram ir à Bolsa de Valores de São Paulo (Bovespa) para levantar capital por meio de oferta pública de ações. Juntas, apenas essas empresas capturaram muito mais que um bilhão de reais. Vejam-se esses dados: a) Anhanguera Educacional, 512 milhões de reais; b) Kroton Educacional, 478,8 milhões de reais; c) Estácio Participações S.A, 447 milhões de reais. (CARTA CAPITAL, 2007)

A intenção dessas empresas é aplicar em EAD 25\% do que foi captado. A rede $C O C$, a que mais tem investido em EAD, entrou na Bovespa, em agosto de 2007. Algumas dessas instituições "apostam no ensino a distância para expandir sua atuação para além dos estados em que estão presentes fisicamente e, até mesmo, no exterior." (BAIO, CINTIA, 2007)

Veja-se o que diz o Clipping Educacional, de maio de 2007:

Embora não revele o valor exato do investimento, resumindo-o em "alguns milhões de reais", como diz Fagundes, a nova modalidade de negócios chega a ficar um terço mais em conta do que montar uma universidade com cursos presenciais. De olho neste mercado também está a Estácio de Sá que, embora não confirmando, encontra-se mergulhada em um grande projeto de ensino a distância, segundo fontes do mercado. A estratégia de criar "universidades virtuais" não se concentra apenas no mercado local. Há planos de levar cursos a distância a brasileiros que vivem no exterior. "Estudamos maneiras de levar 
nosso sistema à África, à Europa e aos Estados Unidos", conta Fagundes, do COC. "Quando ele voltar ao Brasil, não precisa começar a faculdade, já estará formado. O pagamento será de acordo com nossa realidade, o que deve motivar esse mercado." Os planos de internacionalização também estão rondando a universidade Anhembi-Morumbi, em São Paulo. "O ensino a distância é um caminho sem volta e a internacionalização é natural", conta Cristiane Alperstedt, diretora de Educação a Distância. Este ano, a universidade deve contabilizar 10 mil alunos que frequentam disciplinas via web. No segundo trimestre de 2007, a modalidade cresceu $94 \%$ em relação aos primeiros três meses de 2006. "Investimos cerca de $\mathrm{R} \$ 400$ mil em marketing para incentivar as aulas via web", conta Cristiane, mencionando que, desde a entrada do capital estrangeiro na Universidade, os esforços têm crescido, por conta do pedido de seus investidores estrangeiros (GESTÃo EDUCACIONAL, 2007)

Além disso, temos ainda uma grave concentração de oferta de ensino superior no país. Dos 5.561 municípios brasileiros, apenas 1.080 têm cursos superiores e vinte municípios concentram $45 \%$ das matrículas do país, ou seja, têm mais de um milhão e seiscentos mil alunos. Dessa forma, pode-se questionar: como formar professores em nível superior em mais de quatro mil municípios brasileiros sem instituições ou professores para tanto? Junte-se a isso, a grave falta de docentes que o país está vivendo, ou seja, carecemos de mais de 270 mil docentes na Educação Básica.

Essa é a parte visível, uma vez que temos ainda distorções e injustiça nos salários docentes, em especial nos da Educação Básica; temos um gargalo no Ensino Médio, que impede a ampliação de matrículas no ensino superior, como ainda convivemos com poucos recursos para a educação em todos os níveis e também com baixos níveis salariais, o que dificulta a matrícula em instituições privadas.

Ao mesmo tempo em que as relações sociais e os processos de produção simbólica estão cada dia mais midiatizados, digitais, mais se configura uma lógica de lucratividade, de levar vantagens, usando-se as mesmas mídias digitais. É com essa contradição que temos de dialogar, de identificar brechas para uma atuação mais eficaz.

A contradição existente é de que vivemos um processo de transnacionalização da educação e nos vimos requeridos a refletir sobre um modelo de EAD que tenha potencial formador, principalmente no que tange a formação de professores no Brasil.

\section{PARIS X OMC E AS TIC - MITOS MERCADOLÓGICOS}

No art. 12 da Declaração Mundial sobre Educação Superior no Século XXI: Visão e ação (UnEsco, 1998), que aborda o potencial e o desafio da tec- 
nologia, está expresso que as Tecnologias de Informação e Comunicação (TIC), mudarão cada dia mais o modo como o conhecimento é desenvolvido, adquirido, transmitido e oferecem oportunidades de renovar o conteúdo dos cursos e dos métodos de ensino bem como de ampliar o acesso à Educação Superior.

As instituições de ensino superior, de acordo com o mesmo documento, precisam saber aproveitar as vantagens e o potencial das TIC, cuidando da qualidade e mantendo níveis elevados nas práticas e resultados da educação, com um espírito de abertura, igualdade e cooperação internacional, pelos seguintes meios (p. 28):

a) participar na constituição de redes, transferência de tecnologia, ampliação de capacidade, desenvolvimento de materiais pedagógicos e intercâmbio de experiências de sua aplicação ao ensino, à formação e à pesquisa, tornando o conhecimento acessível a todos;

b) criar novos ambientes de aprendizagem, que vão desde os serviços de educação a distância até as instituições e sistemas de Educação Superior totalmente virtuais, capazes de reduzir distâncias e de desenvolver sistemas de maior qualidade em educação, contribuindo assim tanto para o progresso social, econômico e a democratização como outras prioridades relevantes para a sociedade: assegurando, contudo, que o funcionamento desses complexos educativos virtuais, criados a partir de redes regionais, continentais ou globais, ocorra em um contexto de respeito às identidades culturais e sociais; c) considerar que, no uso pleno de novas tecnologias de informação e comunicação para propósitos educacionais, atenção deve ser dada à necessidade de se corrigir as graves desigualdades existentes entre os países, assim como no interior destes, no que diz respeito ao acesso a novas tecnologias de informação e de comunicação e à produção dos correspondentes recursos;

d) adaptar estas novas tecnologias às necessidades nacionais, regionais e locais para que os sistemas técnicos, educacionais, administrativos e institucionais possam sustentá-los;

e) facilitar, por meio da cooperação internacional, a identificação dos objetivos e interesses de todos os países, particularmente os países em desenvolvimento, o acesso equitativo e o fortalecimento de infra-estrutura deste campo e da difusão destas tecnologias por toda a sociedade;

f) seguir de perto a evolução da "sociedade do conhecimento", garantindo, assim, a manutenção de um alto nível de qualidade e de regras que regulamentam o aceso equitativo a esta sociedade;

g) considerar as novas possibilidades abertas pelo uso das tecnologias de informação e comunicação, e perceber que são sobretudo as instituições de Educação Superior as que utilizam essas tecnologias para modernizar 
seu trabalho, e não as novas tecnologias que se utilizam de instituições educacionais reais para transformá-las em entidades virtuais.

Retomando o final do preâmbulo do art. 12 da Declaração, destaca-se a recomendação de que o uso das TIC na Educação Superior deve cuidar da qualidade "com espírito de abertura, igualdade e cooperação internacional". Em relação a esse aspecto, cabem duas observações.

A primeira diz respeito ao Decreto da Presidência da República, de 20 de outubro de 2003, que institui o Grupo Interministerial encarregado de analisar a situação atual e apresentar plano de ação visando a reestruturação, desenvolvimento e democratização das instituições federais de ensino superior (IFES).

Em documento criado por esse grupo interministerial, no elenco de ações emergenciais para o enfrentamento imediato da crítica situação das universidades federais, a EAD e o uso de técnicas de ensino a distância são apontados como os aspectos que podem aumentar a proporção professor(tutor)/alunos de 12,5 no ano de 2004 para 18 em 2007. Desse modo, até 2007 a meta era ter quinhentos mil alunos cursando o ensino superior por meio da EAD. Em 2009, as matrículas de EAD na Educação Superior no Brasil somaram 838.125 , concentrando $16,38 \%$ do total das matrículas, em contraposição ao ensino presencial, com 5.115 .896 matriculados e 83,62\% do total (BRASIL, INEP, 2009; 2010).

Isso é preocupante porque, além do risco de massificação desse nível de ensino (preocupação também expressa nas diretrizes do PNE), mantém-se a visão de EAD com caráter salvacionista, o que historicamente tem-se mostrado inadequado e de certa forma responsável pelos fracassos dos programas e políticas governamentais que tiveram tal compreensão. Agregue-se a isso outro fator, que parece mais preocupante, que é a compreensão de que EAD se faz com poucos recursos e com proporção professor/ aluno maior. $A$ inclusão de tecnologias multimídias agregadas à telemática complexificou a EAD e, por isso, não se pode falar em baixo custo nem em melhorar a proporção professor/aluno. A EAD que utiliza recursos da WEB requer atendimento quase individualizado. Esse é o melhor aspecto, que garante a qualidade dessa modalidade educativa, e ignorá-la é colocar em risco a qualidade que se pretende obter.

Uma política de EAD precisa ser ancorada não apenas em pressupostos econômicos, mas, especialmente, nas possibilidades de democratização que oferece. É com base nesse viés de democratização que as políticas educacionais podem ser exitosas. 
Merece destaque ainda, nesse mesmo documento do grupo de trabalho interministerial, a sugestão que faz à reforma universitária de garantir o futuro da universidade, no que se inclui o uso de: "novos métodos de ensino e convivência universitária, incluindo a universidade aberta e todas as formas de ensino a distância, os reconhecimentos internacionais de saber, os riscos de mercantilização do ensino superior, a formação permanente e a validade dos diplomas." (p. 09 - grifos nossos)

Embora os grifos estejam em itens separados, há de se cuidar para que não explicitem a proposta da Organização Mundial do Comércio, de facilitar a criação de sistemas de acreditação internacional (DıAs, 2002a).

Se a EAD com tecnologias digitais ultrapassa as fronteiras territoriais apenas com cliques em teclas, o país que garantir ou autorizar a certificação internacional, estaria, indiretamente, reconhecendo a educação como serviço, embora não o faça na prática.

Dias (2003a) avalia que a criação da $\mathrm{OMC}^{3}$, em 1995, foi um golpe de Estado mundial. “Criou-se um governo econômico mundial que tem influência na soberania dos países." (p. 33) Ao tirar poder dos governos nacionais eleitos, o perigo é que a OMC exerce um poder sem limites e acumula funções executivas, legislativas e judiciárias, analisa Dias. A OMC "exerce funções legislativas, sendo seus membros obrigados a adaptar suas legislações às normas ali adotadas. É um órgão executivo que exerce também funções de judiciário, através do ORD, órgão que decide sobre as disputas." (p.33).

O que fica evidenciado, segundo análise de Dias (2003b), é que a comunidade universitária está reagindo tardiamente ao Acordo Geral sobre Comércio e Serviços (AGCS), criado em 1994 e à constituição da OMC em janeiro de 1995. “Esta organização foi criada com o objetivo de desenvolver o comércio em todos os setores e dele não abrirá mão" (p. 819), e um dos seus princípios é o de nação mais favorecida, o que significa que se um país da OMC permite a participação em um setor, todos os demais países terão o mesmo direito.

Dias (2002a) observa que a OMC foi, silenciosamente, definindo ações, através de documentos "elaborados ao tempo em que a comunidade internacional se preparava para aprovar a declaração de Paris de 1998. Recentemente, no entanto, foi que as coisas sérias começaram a emergir. Vê-se que uma estratégia foi estabelecida e está sendo seguida com rigor" (p.24). O mesmo autor analisa que a saída para as universidades preocupadas com a Educação Superior como direito e não como serviço a ser prestado com o objetivo de obter lucro, de forma a impedir que a OMC avance com seu projeto de comercialização do ensino superior, além de denunciar, pressionar 
os governos a se posicionarem contra isso, é colocar em prática os princípios adotados em Paris em 1998,

promovendo o acesso, aumentando a pertinência, estabelecendo ações que visem a melhorar a qualidade e o rendimento de contas à sociedade, estudando, com coragem, fórmulas para resolver a difícil questão do financiamento, sem ter que se submeter nem se aviltar diante do mercado, o novo Deus todo poderoso dos que detêm o poder em escala mundial. ( p. 29)

Decidir por esse caminho será tarefa das universidades brasileiras e dos governos; todavia, causa muita preocupação a EAD ser apontada como a modalidade para oferecer serviços educacionais, livremente em todas as nações, sem garantia de respeito às particularidades dos países, por meio de um ensino massificado, como as indicações dos documentos têm assinalado.

Em relação à certificação internacional e referindo-se ao desenvolvimento de um mercado internacional de Educação Superior, Daniel (2003) expressa que "a Unesco não tem a ambição de tornar-se órgão internacional de certificação para a Educação Superior" (p. 159), pois um dos principais desafios nessa tentativa de lidar internacionalmente com a certificação é a legitimidade. "Os consórcios de universidades e os consórcios de empresas privadas podem ser acusados de falhar na sua objetividade ou universalidade." (p. 159-160)

\section{EDUCAÇÃO A DISTÂNCIA - DIREITO X SERVIÇO}

Percebe-se que a liberalização é espaço de complexas situações e os aspectos econômicos são fortes elementos de discussão. A educação a distância aparece nessa discussão como poderoso bem de consumo para alimentar o livre comércio. E a regulação de cada país é premissa importante. Essas características trazem desafios para a educação a distância e consequentemente para a formação de professores.

Essas questões relacionadas à internacionalização da Educação Superior têm sido tema de debates também na UNESCO. Marco Antônio Dias, assessor da UNESCO, em 2002, relatou em entrevista ao Jornal da Universidade, na Reunião de Reitores de Universidades Públicas Ibero-americanas - III Cumbre, que, no âmbito das Conferências Mundiais do Ensino Superior, ficou explícito que a Educação Superior é um serviço público, mas a privatização aparece implicitamente quando cita a diversificação nas modalidades de ensino, inclusive abrindo a possibilidade da educação a distância. Na fala de Marco Antônio Dias, 
no encerramento, os oradores (um foi o Brovetto e outro foi Celine SaintPierre, presidente do Conselho de Ensino Superior de Quebec, Canadá) diziam que se devia impedir as tentativas de comercialização e que o ensino era um serviço público. E a declaração reflete isso: o ensino superior como serviço público (DıAs, 2002b, p. 53).

As discussões no III Cumbre e a Carta de Porto Alegre declaram preocupação com as políticas de favorecimento da comercialização internacional dos serviços da educação traçadas no âmbito da OMC. Marco Antonio Dias relata que as instituições precisam incorporar as novas tecnologias, citando inclusive que, mesmo a tradicional Inglaterra, tem pelo menos $30 \%$ de suas atividades a distância, isso em 1998. Para Dias, "a única maneira, o único caminho que se vislumbra, e tem que ser estudado, é a utilização das novas tecnologias e a cooperação internacional com instituições que tenham uma visão de cooperação solidária." (2002b, p. 61)

Maurício Garcia, Vice-Reitor da Universidade Anhembi Morumbi argumenta, em 2005, que, frente à crise do ensino superior privado brasileiro, três grandes tendências devem ser observadas: segmentação, profissionalização e terceirização.

Um caso sintomático da necessidade de terceirização é o ensino a distância. Dezenas, talvez centenas, de instituições estão fazendo, às suas custas, a implantação desse modelo. Isso implica no desenvolvimento de um software para oferta das aulas (os chamados LMS, ou "learning managemente systems"), na elaboração do conteúdo on line, na compra de servidores, na oferta de links para acesso via internet, no treinamento de tutores, etc. É uma enorme curva de aprendizado e uma repetição inútil do mesmo esforço em vários lugares ao mesmo tempo. A maioria destas instituições irá descobrir, a duras penas, que não tem condições de fazer isso sozinha ou que o custo de torna inviável. Nos próximos anos, será observado o florescimento de uma grande gama de empresas prestadoras de serviços para instituições de ensino. (GARCIA, 2005, p. 43)

O fato é que a educação a distância, tanto com a internacionalização quanto com a privatização, está sendo vista como bem a ser comercializado, com a tendência de tornar-se mercadoria com pacotes prontos. Isso é real, isso é agora, isso não depende das decisões no âmbito da OMC. É uma tendência do impacto vivenciado pelo ensino superior privatizado no Brasil.

Daniel $^{4}$ (2003) identifica três aspectos que denomina triângulo da educação. São eles: acesso, qualidade e custo. Segundo o autor, é um desafio manter um equilíbrio entre esses três vetores, uma vez que, 
quando se tenta melhorar o acesso, proporcionar educação a mais pessoas, corre-se o risco de ser acusado de reduzir a qualidade. Se tentamos cortar os custos, seremos acusados de diminuir a qualidade e o acesso. Ao que parece esta é uma situação impossível para um ministro da Educação, de modo que, para ser realmente útil, a TIC precisará transformar a dinâmica desse triângulo. (2003, p. 151)

Para Daniel, as TIC podem redefinir esse triângulo, com vantagens para todos, isto é, "com mais acesso, melhor qualidade e custos mais baixos" (p. 151). Sublinha que as pessoas evitam falar de custos, mas é pela redução do custo que as tecnologias provocam revoluções.

Compreende-se que a revolução provocada pela informática é de outra dimensão, mas a análise de custos na área de educação não deve ser a mesma que se faz no mundo da produção. Educação não é mercadoria, mas é processo social e, como tal, faz investimento na formação de pessoas; não é simplesmente gasto. Se, no mundo produtivo, a questão dos custos se faz com corte de pessoal, na educação, essa solução não pode ser a principal preocupação, como tem sido no mundo baseado na eficácia, na tecnocracia.

Feenberg (2006) destaca que confundir o meio com suas potencialidades acessórias leva a prever o absurdo de uma educação sem professores. Sabe-se que o déficit de professores que o Brasil vive na área de exatas e biológicas tem sido resolvido com o uso intensivo de teleaulas e monitores, estes quase sempre sem a formação específica para tal. Pensar que as tecnologias irão baratear custos pela redução do número de professores é um equívoco, uma vez que, inversamente, são requeridos mais professores e com uma formação muito mais aprofundada, justamente pela complexidade dessa modalidade educativa.

As licenciaturas atraem menos que outras profissões uma vez seu egresso já sabe, desde a formação, que deverá saber conviver com o desprestígio social da profissão, com os baixos salários, com violência crescente no ambiente escolar e tendo como alunos jovens que não querem estar no espaço da escola e sem o respeito que a profissão docente possuía antes. Poucos desejam enfrentar tamanho desafio.

A Universidade Aberta do Brasil (UAB) surge nesse momento de grave crise de falta de professores, de carência de recursos, de aumento da violência na escola, de desprestígio social e salarial da profissão, e com uma proposta de formação a distância, que também é vista com ressalvas e desconfianças pela sociedade e pela universidade. Entretanto, apesar dos que a assumem serem minoria na universidade, essa é a primeira vez na história da educação brasileira, que a educação a distância está sendo discutida na academia. 
A UAB foi criada em 2005 e é formada por parceria entre consórcios públicos nos três âmbitos governamentais (federal, estadual e municipal). Tem como objetivo: articulação e integração de um sistema nacional de Educação Superior a distância, em caráter experimental. O objetivo do atual governo federal é, por meio da Secretaria de Educação a Distância, promover estratégias de elevar o padrão de qualidade da educação brasileira.

Acrescente-se a esse panorama o fato de que os jovens que chegam à Educação Básica, para o qual os professores estão sendo formados, são "nativos digitais" (PrensKY, 2007), ou seja, têm a singularidade de terem nascido num ambiente societário cheio de tecnologias digitais, e possuem conhecimento das linguagens variadas e próprias desse novo ambiente. Esses jovens têm habilidade, sociabilidade, cognição e afetividade diferentes das gerações que os precederam. Como lembra Babin (1989), isso é resultado de dezenas de anos com televisão, cinema, aparelhos eletrônicos e agora computadores e Internet.

Certamente, um professor que dê conta de atuar junto a esse jovem, conservando sua alegria e motivando-o a aprender, precisa ter uma formação inicial ou continuada diferente da que tem sido realizada em nossos cursos de formação de docentes.

Quem sabe cursos mediados por computadores possam ser uma possibilidade de ruptura com os modelos em vigência? As TIC, as mídias digitais, possibilitam estudo por descoberta. “O processo de aprendizagem, mediado por tecnologia informacional, ocorre por descobrimento (exploração), não por imitação (reprodução), predominante na educação escolar." (OROzco, 2006, p. 97)

Quando se fala sobre EAD, todavia, é preciso identificar de qual EAD se fala. Há diferentes modelos e vale a pena conhecê-los para se saber a qual deles uma determinada proposta de EAD se aproxima, filia-se ou adere. Belloni (2001) identifica dois modelos: o fordista e o pós-fordista. Feenberg (2006), um pioneiro da $E A D$, refere-se também a dois modelos: o da fábrica e o da cidade. Enquanto os primeiros modelos, o fordista e o da fábrica, ocupam-se de EAD de massa, com oferta em massa de cursos que oferecem produtos estandardizados, com mínima ou nenhuma interação pessoal e crítica, com planejamento centralizado, os segundos modelos, o pós-fordista e o da cidade, interativos, valorizam as atividades de comunicação que proporcionam trocas permanentes entre ensinantes e aprendentes; possuem planejamento flexível de forma a garantir a diversidade e a diferenciação no planejamento do curso. 
Desse modo, o modelo de massa, chamado também de broadcasting, valoriza os pacotes educacionais, burocratiza as tarefas, centraliza o planejamento e, por ter alta relação do número de alunos por professor, não aproveita a interação propiciada pela rede, fazendo com que os estudantes desse tipo de curso sintam-se isolados.

Já o modelo interativo, por ter baixa a relação do número de alunos por professor, valoriza o estar junto de professores e alunos, de alunos e alunos, com atendimento mais individualizado, contrastando com o modelo da fábrica, que não tem o compromisso com a interação, com a construção do conhecimento, com a criticidade, mas tem como objetivo angariar recursos de um número maior de alunos, não importando se estão se formando ou não com a qualidade desejada.

Infere-se dessas teorias que é o tipo da proposta e o modelo de EAD usado que dão qualidade a um curso em EAD e não a inovação tecnológica ou a sofisticação da tecnologia usada. Litwin (2001) dá importantes referências para um bom programa de EAD; são elas: a) ter conteúdos atualizados e enfoques novos; b) identificar conceitos relevantes e desenvolver polêmicas e reflexões; c) possuir corpo docente preocupado com a compreensão dos alunos; d) ter docentes que pesquisam no seu campo de atuação e se preocupam em alimentar e favorecer os processos de aprendizagem; e) contar com professores que convertam suas experiências em casos, situações e exemplos, para favorecer uma educação permanente. A mesma autora assevera que é fundamental "a avaliação permanente do projeto junto à equipe que o executa e aos alunos, de forma a identificar êxitos e problemas." (p. 19)

O novo meio da EAD exige uma visão mais construtivista e interacionista, em oposição ao instrumentalismo e à competitividade dominante (Gomez, 2004). Dessa forma, é preciso superar a polêmica do "ser contra" versus "ser a favor" das tecnologias na educação (p. 18).

O Exame Nacional de Desempenho dos Estudantes (Enade), criado em 2004, incluiu pela primeira vez, em 2006 cursos presenciais e a distância, o que permite relacionar o desempenho dos mesmos cursos nas duas modalidades. "Em sete das 13 áreas onde essa comparação é possível, alunos da modalidade a distância se saíram melhores do que os demais." (FOLHA DE S. PAULO, 2007)

Na comparação entre ingressantes e concluintes, os resultados são ainda mais favoráveis aos estudantes da educação a distância: em nove das 13 áreas, o resultado foi melhor. Turismo e Ciências Sociais apresentaram a maior vantagem favorável aos cursos a distância. Geografia e História foram os cursos em que o ensino presencial apresentou melhor desempenho. 
Entre os concluintes, o melhor desempenho para estudantes a distância foi verificado em Administração e Matemática. Entretanto, em Pedagogia e formação de professores (Normal Superior), o resultado foi inverso. Esse resultado traz ainda mais esse complicador para a formação de professores.

Se os cursos a distância que temos não têm sido dos melhores modelos, por que alguns estudantes de cursos a distância se saíram bem neles? Por que foram justamente os formados em licenciatura que apresentaram os piores resultados? Seria essa modalidade negativa apenas para os cursos de formação de professores? Qual o diferencial entre concluintes dos bacharelados e das licenciaturas? Por essas e inúmeras outras questões infere-se que há ainda muito a pesquisar e conhecer sobre essa forma de educação.

PARA NÃO FINALIZAR...

Após apresentar o retrato parcial da EAD no país no que tange ao ensino superior, ter citado a legislação referente à modalidade EAD e também referir-se às TIC, suas linguagens e abordagens teórico-pedagógicas sobre a $E A D$, pensa-se que é possível analisar as perspectivas da EAD no Brasil. Para isso, a proposição vai impregnar as próximas linhas, de forma, inclusive, a propiciar a reflexão sobre o que seria preciso fazer para evitar os equívocos de muitas experiências em EAD. Isso é particularmente relevante porque ações mais globais com grande número de envolvidos, sem, porém, a característica de políticas e programas massificadores, requerem planejamento cuidadoso, coletivo, que envolva diferentes áreas do conhecimento e, sobretudo, sejam políticas de gestão da educação a distância.

Um dos principais riscos desse processo é, conforme Feenberg (2003), vender um novo modelo econômico de educação sob o disfarce de um novo modelo tecnológico. Antes de qualquer coisa, vale registrar o pressuposto de que os cursos a distância precisam garantir que a Educação Superior ocorra na perspectiva e compreensão dela como direito, como bem público, dever do Estado e condição de cidadania. Nesse sentido, o uso de recursos deve ser compreendido como investimento humano e não como gasto, como tem sido preocupação generalizada.

Uma política de Educação Superior a distância que deseja pautar-se pelo respeito à educação como direito, como bem público, deve levar em conta a distribuição desigual das vagas no ensino superior. Assim, é preciso estimular a oferta e buscar o atendimento de estados e municípios mais carentes desse nível de ensino e deve-se garantir a infra-estrutura para os telecentros, antes mesmo de dar início às políticas e programas específicos. Isso é fundamental para não se destruir a nova imagem de EAD que se busca 
construir com o apoio das universidades públicas. É a primeira vez na história da EAD no Brasil que se tem o apoio das universidades, não se podendo, por isso, queimar precocemente essa parceria.

Silveira (2001) alerta para a importância da inclusão digital. Para ele, a inclusão social passa pela inclusão digital, não apenas para acesso aos equipamentos e sua manipulação, mas, sim, porque é por essa tecnologia midiática que circula a informação em todo o mundo. Dessa forma, o oferecimento de cursos a distância que usem a Internet deve possibilitar, inicialmente, o acesso às tecnologias. A criação de telepostos em cidades estratégicas dos diferentes estados brasileiros é uma forma de democratizar o acesso a quem está excluído da tecnologia de base computacional, como é oportunidade de descentralizar o oferecimento da graduação, uma vez que, em geral, os cursos de graduação concentram-se nas maiores cidades. Cerca de $72 \%$ das vagas dos vestibulares de 2002 foram oferecidas nas regiões Sul e Sudeste do país (BRASIL, 2004).

A visão determinista de tecnologia está superada pela compreensão de que somos nós que escolhemos o uso a ser dado à tecnologia. Ela, por si só, não faz a reforma na educação. O futuro da tecnologia na educação depende da comunidade educacional, depende de como esta expressará sua resistência à automatização na educação.

Muito embora a EAD tenha sido apontada como modalidade a ser usada na ampliação dos serviços educacionais e organismos globais busquem isso, os países, fazendo uso de sua soberania, podem fazer a contraofensiva preparando-se técnica e conceitualmente para esse enfrentamento, que é tanto econômico como de concepções.

Para finalizar, retoma-se a epígrafe que inicia este texto, a qual anota a existência de diferentes sociedades da informação. Somos nós, brasileiros, que vamos definir qual desejamos e trabalhar por ela. Evidentemente, o conflito será grande. A tarefa é hercúlea e não admitirá amadorismo. O jogo começou, as regras nem sempre são muito claras, mas é preciso preparar-nos para esse combate no qual a formação de professores está em pauta. 


\section{TEACHERS'TRANING IN THE CONTEXT OF THE TENDENCIES OF INTERNATIONALIZA- TION OF HIGHER EDUCATION AT DISTANCE}

ABSTRACT: the text discusses the relationship of distance education with the policies of internationalization of higher education and inclusion of teacher training in this reality. Shows that distance education is booming, especially in training courses for teachers, and immersed in the process of trade liberalization within the WTO. In this process of liberalization, the EAD is being seen as a commodity whose characteristics of transfronteirização and low cost. Raises the question of the necessity of discussing the DL in Brazil as well as a consumer and the importance of discussions around their offer conditions, objectives and rules.

KEYWORDS: Higher education in the distance. Internationalization of education. Teacher Training.

\section{NOTAS}

1. Apresentado como Comunicação no XXIV Simpósio Brasileiro de Política e Administração da Educação e III Congresso Interamericano de Política e Administração da Educação realizado em Vitória/ES em 2009, sob o título "Tendências para internacionalização da Educação Superior e a educação a distância".

2. "O mercado da educação privada no Brasil faturou no ano de 2003 o total de 35,5 bilhões de reais, sendo que de todos os níveis, o ensino superior foi o mais lucrativo, faturando 14,9 bilhões, seguido pelo ensino fundamental, com 13,3 bilhões [...]. Sob a mesma ótica, a Faculdade Anhembi Morumbi de São Paulo teve $51 \%$ de sua participação comprada por um grupo educacional americano (o Grupo Laureate), no valor de R\$ 158 milhões [...]. Em transação similar, a Anhangüera Educacional, do interior de São Paulo, recebeu investimentos da ordem de US\$ 12 milhões do Banco Mundial, por meio de seu braço privado, a International Finance Corporation" (IFC) (BAnCO..., 2006)" (OYAma, 2007, p. 13).

3. As áreas de serviços que a OMC deseja cobrir são: os serviços fornecidos às empresas (os profissionais e informáticos), os de comunicação, os de construção e de engenharia a ele vinculados, os de distribuição, os ligados ao meio ambiente, os financeiros (seguro e bancários). Incluem ainda, além da educação: os de saúde e serviços sociais, os relativos ao turismo e às viagens, os recreativos, culturais e esportivos, os de transporte e outros serviços não incluídos na lista mencionada.

4. John Daniel é diretor geral adjunto para a educação da Unesco e ex-reitor da Universidade Aberta do Reino Unido, que tem 150 mil alunos a distância. No livro que serviu de base às idéias de Daniel, apresentadas neste texto, o autor se concentra na análise da Educação Superior que faz uso das TIC, expressando as posições e a compreensão que a organização que dirige tem sobre os problemas educacionais do mundo de hoje, em especial do uso das TIC. 


\section{REFERÊNCIAS}

ABRAED (Associação Brasileira de Educação a Distância). Anuário Brasileiro Estatístico de Educação Aberta e a Distância, 2007. 3. ed. São Paulo: Instituto Monitor, 2007.

BABIN, P.; KOULOUMDJIAN, M. F. Os novos modos de aprender - a geração do audiovisual e do computador. São Paulo: Paulinas, 1989.

BAIO, C. São Paulo, disponível em <http://blog.controversia.com.br/category/geral> Acesso em 29 de Agosto de 2007 às 15h 28m

BANCO MUNDIAL. La enseñanza superior: las lecciones derivadas de la experiência. Washington: Banco Mundial, 1995.

BELLONI, M. L. Educação a distância. Campinas, SP: Autores Associados, 2001

BRASIL, INEP. Instituto Nacional de Estudos e Pesquisas Educacionais Anísio Teixeira. Sinopse da Educação Superior 2009. Brasília: INEP, 2010.

. Resumo Técnico - Censo da Educação Superior 2008. Brasília: INEP, 2009.

BRASIL, MEC/INEP. Sinopse Estatística da Educação Superior-Censo 2007. Brasília, 2007. Disponível em: www.inep.gov.br Acesso em 17.05.2009.

. Sinopse Estatística da Educação Superior-Censo 2000. Brasília-DF, 2001.

Disponível em <www.inep.gov.br> Acesso em 18.02.2004.

, MEC/UNDIME/CONSED. Plano Nacional de Educação - subsídios para a elaboração dos Planos Estaduais e Municipais de Educação. Brasília-DF, 2001.

CARTA CAPITAL, 17 de outubro de 2007, no 466, p. 10-15.

DANIEL, J. Educação e tecnologia num mundo globalizado. Brasília: Unesco, 2003.

DIAS, M. A. Dez anos de antagonismo nas políticas sobre ensino superior em nível internacional. Educação \& Sociedade. Campinas, v. 25, n. 88, p. 893-914, out. 2004.

. OMC: um golpe de Estado Mundial. In: CÂMARA DOS DEPUTADOS. Educação: mercadoria de exportação. Brasília: Câmara dos Deputados, 2003a.

. Comercialização no ensino superior: é possível manter a idéia de bem público? Revista Educação \& Sociedade. V. 24, n. 84, São Paulo: Cortez, Campinas: Cedes, 2003 b. p. 817-838.

. Educação superior: bem público ou serviço comercial regulamentado pela OMC? Versão provisória. s.n.t., maio de 2002a (mimeo).

. Estamos vivendo um período de obscurantismo. In: ROCHA, S. M.; NETTO, C. A. Universidade Pública, educação e desenvolvimento: reflexões da III Cumbre - Reunião de Reitores de Universidades Públicas Ibero-americanas. Porto Alegre, 2002b.

FEENBERG, A. La enseñanza "online" y las opciones de Modernidad. Disponível em $<$ http://www.sfu.ca/ andrewf/pensamiento.pdf> . Acessado em maio de 2006. 
FLORES JR, R. O GATS e os serviços de Educação Superior: o que devemos fazer? Estudos - Revista da Associação Brasileira de Mantenedoras de Ensino Superior (ABMES), Brasília, abr. ano 22, n. 33, p. 27-34. 2004.

FOLHA DE S.PAULO (Folha On Line). Aluno a distância vai melhor no Enade. São Paulo, 10.09.2007. Disponível em <http://www1.folha.uol.com.br/folha/educacao/ ult305u327081.shtml> Capturado em setembro de 2007.

GARCIA, M.. Três grandes tendências para o ensino superior privado no Brasil. Revista Ensino Superior, n. 77, São Paulo, p. 41-43, fev. 2005.

GOMEZ, M.V. Educação em rede - uma visão emancipadora. São Paulo: Cortez: Instituto Paulo Freire, 2004.

GRISI, C. C. H. Negociações em torno do acordo geral sobre comércio e serviço. Estudos - Revista da Associação Brasileira de Mantenedoras de Ensino Superior (ABMES), Brasília, ano 22, n. 33, p. 17-26, abr. 2004.

LITWIN, E. Educação a distância - temas para o debate de uma nova agenda educativa. Porto Alegre: Artmed, 2001.

OROZCO GÓMEZ, G. Comunicação social e mudança tecnológica: um cenário de múltiplos desordenamentos. In: MORAES, D. (org.). Sociedade midiatizada. Rio de Janeiro: Mauad, 2006, p. 81-117

PRENSKY, M. Digital natives, digital immigrants. Disponível em: <http://www.marcprensky.com/writing/Prensky\%20-\%20Digital\%20Natives,\%20Digital\%20Immigrants\%20-\%20Part1.pdf >. Tradução: Pedro Seabra A. Toschi. Acessado em novembro de 2007.

OYAMA, Edison Riuitiro. A democratização do ensino com Anísio Teixeira versus educação brasileira em tempos de neoliberalismo. Trabalho Necessário. Universidade Federal Fluminense, Faculdade de Educação. Ano 5, número 5, 2007. Disponível em <http://www.uff.br/trabalhonecessario/>. Acesso em 08/12/2007.

RANIERI, N. O que há de novo na internacionalização da Educação Superior? Estudos - Revista da Associação Brasileira de Mantenedoras de Ensino Superior - ABMES, Brasília, ano 22, n. 33, p. 7-16, abr. 2004.

GESTÃO EDUCACIONAL. Disponível em: <http://www.gestaoeducacional>. Acesso em: $12 /$ maio/2007.

SANTOS, B. S. Pela mão de Alice: o social e o político na pós-modernidade. 3. ed. São Paulo, Cortez, 1997.

SGUISSARDI, V. O desafio da Educação Superior no Brasil: quais são as perspectivas? In: (org.). Educação Superior: velhos e novos desafios. São Paulo: Xamã, 2000.

SILVEIRA, S. A. Exclusão digital - a miséria na era da informação. São Paulo: Fundação Perseu Abramo, 2001. 
UNESCO. Conferência Mundial sobre Educação Superior - Paris, 1998. Piracicaba: Editora da Unimep, 1998.

Mirza Seabra TOSCHI é doutora em Educação, aposentada pela FE/ UFG e professora da UnUCSEH/UEG e do mestrado em Sociedade, Tecnologia e Meio Ambiente da UniEvangélica. Em 2010, fez estágio de pós-doutoramento na $\mathrm{FE} / \mathrm{Un}_{\mathrm{n}}$, onde teve como supervisora IIma Passos Alencastro Veiga.

E-mail:mirzas@brturbo.com.br; mirzas@smail.com

Juliana Guimarães Faria é graduada em Pedagogia pela Universidade Federal de Goiás (2001), especialista em Informática em Educação pela UFLA (2003) e em Avaliação Institucional pela UEG (2005); mestra em Educação pela Universidade Federal de Goiás (2005) e, atualmente, cursa o Doutorado em Educação na FE/UFG e é professora de Fundamentos Filosóficos e Sócio-Históricos da Educação de Surdos e Políticas da Educação de Surdos no Brasil, no curso de Letras da FL/ UFG.

Email: julianasł@yahoo.com.br 